\title{
The Clinical and Theoretical Trends of Music Therapists: The Israeli Case
}

\author{
Chava Wiess ${ }^{1 *}$, Ayelet Dassa ${ }^{2}$, Avi Gilboa ${ }^{2}$ \\ 1 David Yellin College, Jerusalem, Israel \\ 2 Israel Bar-Ilan University, Ramat-Gan, Israel \\ *wiessc@gmail.com
}

Received: 3 August 2016 ; Accepted: 16 January 2017 ; Published: 1 March 2017

\begin{abstract}
In the present study we conducted a first of its kind online survey of music therapists (MTs) in Israel. Though this field has been growing rapidly and to date includes about 700 MTs, there was not yet a survey conducted to adress their fields of interest, and their clinical and theoretical orientations. A total of 107 MTs, 48 of which had more than 8 years of experience (MEMT) and 57 of which had less than 8 years of experience (LEMT), answered an internet survey examining: (a) the instruments and the techniques they use, (b) the populations they work with, and (c) their theoretical orientation. Results indicated significant differences between MEMTs and LEMTs in almost all fields of inquiry. Generally, most of the younger generation is open to more techniques, proficient with more instruments, and uses more music in their work. In a continuously globalizing world, the results of this study are relevant to not only Israeli music therapists, but others as well since the local situation captured in this study can be compared and related to the situations in other countries. Recommendations are provided for places where such studies and surveys have not yet been conducted.
\end{abstract}

Keywords: Music therapy, professional identity, clinical orientation, online survey

\section{Surveying the Clinical and Theoretical Trends of Music Therapists: The Israeli Case}

Surveys conducted to research the music therapy profession have been a widespread and effective tool in past decades, especially in the United States (Clark \& Kranz, 1996; Curtis, 2013; Kern, Rivera, Chandler, \& Humpal, 2013). Such surveys enable the profession and its policy decision makers to obtain the bigger picture and see what should be maintained and what should be improved (Curtis, 2013; Jenkins, 2013). In such surveys, a large number of music therapists (MTs), usually nation-wide, are invited to participate, and the response obtained according to Sheehan (2001), typically between $25 \%$ and $35 \%$, enables tentative generalizations about the studied subject. With the development of online tools, such surveys have been more accessible and, therefore, more prevalent.

Several surveys have addressed the preferences of MTs within a specific client population. Jackson (2003) investigated methods in the treatment of children with attention deficit hyperactivity disorder (ADHD) and found that MTs did not use one specific method with these children but rather utilized various music therapy methods to ad- 
dress multiple goals. Silverman's (2007) survey focused on the clinical objectives of music therapists working in psychiatric settings and found that the music therapists predominantly addressed goals such as socialization, communication, self-esteem, coping skills, and stress reduction/management in a group music therapy setting. Kern et al. (2013) surveyed music therapists working with clients with autism spectrum disorder (ASD) and found that this population was treated primarily in public schools but also in home and community settings.

Other surveys were not limited to a particular clinical population but rather focused on the attitudes of MTs, music therapy students included, towards different issues. Cohen, Hadsell \& Williams' (1997) study, for instance, investigated the attitudes of music therapy students and clinicians towards their applied instrument requirements. A comparison between music therapy students and clinicians regarding the importance of studying an applied instrument found that both clinicians and students agreed on the overall clinical importance of applied performance to success as a music therapist. Results also showed that voice and keyboard were the most frequently applied instruments for both students and practicing clinicians.

Clark and Kranz's (1996) survey focused on music therapy students and examined their background, attitudes, and expectations, thus providing an indication as to how they view the profession. Regarding types of settings in which MTs were employed, students reported medical and school settings as the most common. Although mental illness and related disorders accounted for the largest segment of actual professional practice, students identified "children" as the most desired field of clinical work. Despite this desire, many of the respondents actually worked with other populations.

Curtis (2013), who surveyed North American MTs, was interested in a possible developmental change in the profession throughout the years. To do this, she compared present-day MTs with their 1990 counterparts in terms of their approaches. She found that present-day female MTs were older, more educated, more often in academic settings, and more satisfied with their career choice compared to their 1990 counterparts. Findings also revealed that present day MTs shared a passion for their work and recommended music therapy careers almost twice as much as MTs in the 1990 survey.

Despite the fact that nation-wide surveys can be effective, they have not yet been conducted in many countries, including in Israel. Music therapy in Israel began sporadically in the 1970s and was formalized in the early 1980s, when three training programs were founded: (1) The music therapy program at David Yellin College of Education, founded by Dr. Chava Sekeles; (2) the music therapy program at Bar-Ilan University, founded by Prof. Dorit Amir; and (3) the music and dance therapy program at Levinsky founded by Dalia Razin College (Goodman, 2011). Naturally, the founders of the programs shaped them according to their clinical orientation. To give some examples, Dr. Chava Sekeles, being an occupational therapist, incorporated many ideas from this profession in the David Yellin program. Professor Dorit Amir graduated from the New York University (NYU) program and incorporated many of the psychodynamic and humanistic ideas that were central there to the Bar-Ilan program. Both these founders, being deeply dedicated to music and to music making, accentuated the importance of music and music making (and less so, talking about the music) in the MT process. Dalia Razin, to compare, being herself a dance therapist, formed a joint "music and dance therapy program" at the Levinsky program.

During the past decade some very important changes occurred. First, all programs developed from granting a post-bachaloriate diploma to granting a full master's degree. Second, a fourth music therapy program was founded at Haifa University headed by Dr. Cochavit Elefant ${ }^{1}$. Many of the community and participatory ideas she absorbed in her stay in Northern Europe, first as doctoral student, then as lecturer and researcher, were incorporated in this program. Finally, in 2012, a program for ultra-orthodox women headed by Dr. Avi Gilboa ${ }^{2}$ was founded. This program is a branch of the BarIlan program, so it is directly influenced by Bar-Ilan's curricula. However, it is continuously challenged by the fact that the students are from a strictly religious background so that cultural adjustments are constantly made. To date, there are approximately 700 
MTs in Israel and they work with an ever-growing clinical population within Ministry of Education schools, kindergartens, and special education centers, and within Ministry of Health hospitals and treatment centers (Goodman, 2011; Gottfried, 2015). The Israeli Association of Creative and Expressive Therapies (ICET), under which MTs work, enables them to hold a certified status. We feel that with such a considerable number of music therapy programs and music therapists and with such changes occurring in the legislation and the definition of the profession in the country and worldwide, it is essential to conduct a nation-wide survey to obtain an initial perspective on music therapy in Israel, if and how it is changing, and consequently to understand if and how it should be moving forward.

\section{The Present Study}

In the present study we examined, as broadly as possible, the Israeli milieu of MTs. We wanted to know what techniques they use, what populations they attend to, and how they define their theoretical orientation. We were also interested to see the breakdown of these questions with regard to the level of MTs' experience: Do less experienced MTs give different answers than more experienced ones? Such a perspective could help to assess whether developments in training courses may be helpful or not for MTs working in the field. As MTs who have influence on decisions made in our milieu, such information provided an updated picture regarding the current state of the profession, and ideas regarding possible changes that may be required.

To achieve these goals, we initiated an online survey that was sent to MTs on alumni lists of all of the training programs in Israel.

The survey included questions that reflect: (a) the instruments and music therapy techniques that MTs use; (b) the populations and age groups that MTs work with and the population(s) they prefer to work with; (c) the MTs' theoretical orientation (e.g., music as therapy vs. music in therapy, verbally vs. musically oriented music therapy, and psychological theoretical framework). The research questions were:

- What are the instruments and techniques, the clinical populations, and the theoretical orientations of MTs in Israel?

- Are there any differences between less experienced and more experienced MTs in regard to these factors?

Because of the preliminary nature of this study, no hypotheses were made.

\section{Method}

\section{Participants}

One hundred and seven (107) MTs that live and work in Israel participated in the study, all of whom were trained as MTs in Israel. There were 85 women and 22 men and a balanced distribution of training programs from which they graduated: 41 graduated from the Levinsky program, 23 graduated from the David Yellin program, 35 graduated from the Bar-Ilan program (including the Haredi College), and 8 graduated from the newly established Haifa University program. The age distribution was as follows: 8 MTs were between 25 and 30; 32 between 31 and 35; 16 between 36 and 40; 15 between 41 and 45; 12 between 46 and 50; 24 aged 51 and older. The median age was 38. Experience wise, participants were distributed as follows: 24 MTs had 1 to 3 years of experience; 34 had 4 to 8 years of experience; 23 had 9 to 15 years of experience; 13 had 16 to 20 years of experience; 13 had 21 years of experience and more. The median of this variable was 8 years of experience.

\section{Tools}

An online survey was devised for the purpose of this study. Items in the survey included demographic questions (e.g., age, gender, seniority, training program, etc.); questions regarding the instruments and techniques MTs used and felt most proficient with 
(e.g., "What do you consider your primary instrument? What is your secondary instrument?", "What techniques do you feel most comfortable with?"); questions regarding preferred populations (e.g., "What population group do you feel most comfortable working with?"; "What age group do you feel most comfortable working with?"33); and questions regarding the theoretical orientation of the MTs (e.g., "How do you define your treatment approach: music in therapy, music as therapy?", To what extent are your treatments verbal? Musical?"; "Do you work according to a pre-defined psychological approach? If so, what is it?"). A pilot study with a draft version of the survey was conducted. Twenty MTs answered the survey and questions were subsequently revised and edited. A final version with 31 questions was used.

\section{Procedure}

The survey, a Google Doc, was sent electronically to 396 MTs whom we found a way to contact ${ }^{4}$. To facilitate this, a link to the survey was sent to all Music Therapy Program Heads in Israel, to be disseminated to their alumni lists. In addition, the link to the survey was sent to numerous MTs that supervise and train music therapy students in various work places. The questionnaires were also sent to various mailing lists containing MTs. Once a week, a reminder was sent to the mailing lists. After 2 months, the survey ended and 107 MTs replied (response rate of 27\%). Data were organized in an SPSS data file and then analyzed by a proficient statistician.

\section{Results}

Participants were divided according to the median of seniority (Median $=8$ years of experience), which resulted in a group of 58 less-experienced MTs (LEMT) and 49 more-experienced MTs (MEMT).

\section{Main Musical Instruments and Music Therapy Techniques}

Participants were asked to indicate the two instruments (primary and secondary) that they felt most proficient with. Results are presented in Table 1, separately for MEMTs and LEMTs. For the MEMTs, the piano was highly dominant $65.3 \%$ of the MEMTs reported it as their primary instrument), and the other instruments were more marginal. For the LEMTs, in contrast, both the piano and the guitar were reported as their primary instrument $(75.8 \%$ of the LEMTs reported one or the other as their primary instrument), and other instruments were marginal. Regarding the secondary instrument, the MEMTs and LEMTs had different profiles here, as well. While $56.3 \%$ of the MEMTs reported the guitar as their secondary instrument, LEMTs reported both guitar and piano as their secondary instrument (67.2\%). MEMTs and LEMTs were similar, however, in that the piano and the guitar, taken together, were the most dominant instruments. Independent $t$-test revealed no significant differences between LEMTs and MEMTs regarding their confidence playing their primary instrument $(M=4.1, S D=0.86$ vs. $M=3.9, S D=0.95$, respectively). However, differences were found regarding confidence playing the secondary instrument: LEMTs felt more confident in comparison to the MEMTs $(M=3.3, S D=1.09$, vs. $M=2.7, S D=1.04$, respectively; $t(105)=$ $2.63, p<0.01)$. In addition, LEMTs were more confident using their voice in comparison to MEMTs $(M=4.04$. $S D=0.97$, vs. $M=3.43, S D=1.1$, respectively; $t(105)$ $=3.02, p<0.001$ ).

Participants were asked what techniques they used and to what extent. Figure 1 shows this information, comparing MEMTs and LEMTs.

A two-way repeated measure analysis of variance with musical technique as a within subject factor, and seniority as a between subject factor showed that there was a significant difference between the extent to which different techniques were used $(F(4,101)$ $=93.8, p<0.001]$. Improvisation $(M=5.0)$ and existing songs $(M=4.9)$ were the most highly rated, songwriting $(M=3.5)$ and vocal improvisation $(M=3.6)$ were intermediate, and Guided Imagery in Music (GIM) was used the least $(M=2.4)$. Gen- 
Table 1

Reports of MEMTs and LEMTs regarding their primary and secondary instruments (in percentages)

\begin{tabular}{|c|c|c|c|c|c|c|c|}
\hline & Piano & Guitar & Drums & Voice & $\begin{array}{c}\text { String } \\
\text { instrument }\end{array}$ & $\begin{array}{c}\text { Wind } \\
\text { instrument }\end{array}$ & Total \\
\hline \multicolumn{8}{|c|}{ Primary instrument } \\
\hline MEMT & 65.3 & 10.2 & 2.0 & 8.2 & 0.0 & 14.3 & 100.0 \\
\hline LEMT & 53.4 & 22.4 & 5.2 & 8.6 & 5.2 & 5.2 & 100.0 \\
\hline Average & 58.9 & 16.8 & 3.7 & 8.4 & 2.8 & 9.3 & 99.9 \\
\hline \multicolumn{8}{|c|}{ Secondary instrument } \\
\hline MEMT & 18.8 & 56.3 & 6.3 & 10.4 & 4.2 & 4.2 & 100.2 \\
\hline LEMT & 24.1 & 43.1 & 13.8 & 12.1 & 0.0 & 6.9 & 100.0 \\
\hline Average & 21.7 & 49.1 & 10.4 & 11.3 & 1.9 & 5.7 & 100.1 \\
\hline
\end{tabular}

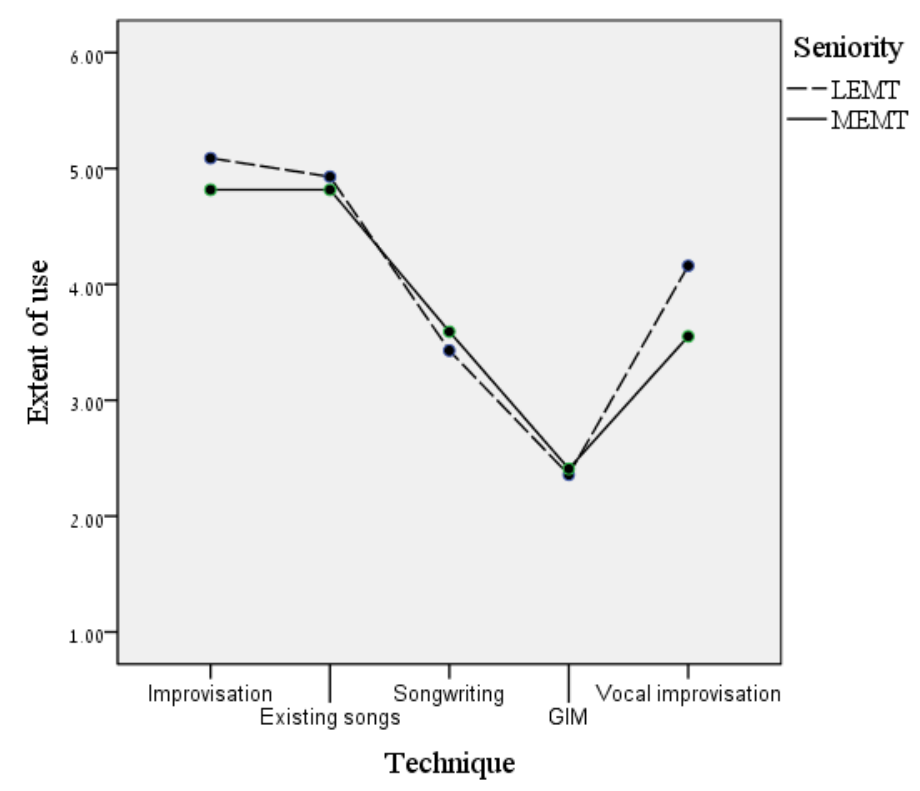

Figure 1

Music therapy techniques used by MEMTs and LEMTs

erally, there were no significant differences between MEMTs and LEMTs except for a higher use of vocal improvisation among the LEMTs $(M=4.1)$ compared to the MEMTs $(M=3.6, t(104)=2.0, p<0.05)$.

\section{Clinical Populations}

MTs were asked to indicate which clinical population they preferred to work with. Table 2 shows the results, comparing MEMTs and LEMTs.

Overall, the population the participants most preferred to work with were clients with emotional disabilities (38.5\%), and the least preferred clients were those with physical disabilities (3.8\%), youth at risk (5.8\%), and older adults (5.8\%). A breakdown into MEMTs and LEMTs shows, however, different fields of preference. While the MEMTs indicated clients with emotional disabilities as their foremost preferred population $(50.0 \%)$, and clients with physical disabilities $(2.2 \%)$, clients with intel- 
Table 2

Distribution of Respondents According The Population They Prefer to Work with and Their Seniority (in percentages).

\begin{tabular}{|l|l|l|l|l|l|l|l|l|l|}
\hline & Autism & $\begin{array}{c}\text { Intellectual } \\
\text { Disability }\end{array}$ & $\begin{array}{c}\text { Youth at } \\
\text { risk }\end{array}$ & $\begin{array}{c}\text { Older } \\
\text { Adults }\end{array}$ & $\begin{array}{c}\text { Learning } \\
\text { disabilities }\end{array}$ & $\begin{array}{c}\text { Emotional } \\
\text { disabilities }\end{array}$ & $\begin{array}{c}\text { Mental } \\
\text { disabilities }\end{array}$ & $\begin{array}{c}\text { Physical } \\
\text { disabilities }\end{array}$ & Total \\
\hline MEMT & 6.5 & 2.2 & 2.2 & 8.7 & 13.0 & 50.0 & 15.2 & 2.2 & 100.0 \\
\hline LEMT & 29.3 & 10.3 & 8.6 & 3.4 & 5.2 & 29.3 & 8.6 & 5.2 & 99.9 \\
\hline Overall & 19.2 & 6.7 & 5.8 & 5.8 & 8.7 & 38.5 & 11.5 & 3.8 & 100.0 \\
\hline
\end{tabular}

Table 3

Distribution of Respondents According to the Age Group They Prefer to Work with and Their Seniority (in percentages)

\begin{tabular}{|l|l|l|l|l|l|l|}
\hline & Toddlers & Children & Adolescents & Adults & $\begin{array}{c}\text { Elderly } \\
\text { people }\end{array}$ & Total \\
\hline MEMT & 6.3 & 52.1 & 14.6 & 20.8 & 6.3 & 100.1 \\
\hline LEMT & 33.3 & 26.3 & 22.8 & 12.3 & 5.3 & 100.0 \\
\hline Overall & 21.0 & 38.1 & 19.0 & 16.2 & 5.7 & 100.0 \\
\hline
\end{tabular}

lectual disability $(2.2 \%)$, and youth at risk $(2.2 \%)$ as their least preferred population, LEMTs indicated both clients with emotional disabilities (29.3\%) and clients with autism $(29.3 \%)$ as their preferred populations, and older adults (3.4\%) and clients with physical (5.2\%) and learning (5.2\%) disabilities as their least preferred populations. A chi-square analysis showed that the differences between the preferences of MEMTs and LEMTs were significant $\left(x^{2}(7)=19.34, p<0.01\right)$.

MTs were asked to indicate which age group they prefer to work with. Table 3 shows the results, comparing MEMTs and LEMTs.

Overall, the MTs preferred to work with children (38.1\%) and they least preferred to work with older adults (5.7\%). When referring separately to MEMTs and LEMTs, significant differences were found. While MEMTs preferred working with children (52.1\%) and adults (20.8\%), LEMTs preferred to work with toddlers (33.3\%), children (26.3\%), and adolescents $(22.8 \%)$. A chi-square analysis showed that the differences between the preferences of MEMTs and LEMTs were significant $\left(x^{2}(4)=17.1, p<0.01\right)$.

\section{Theoretical Orientation}

MTs were asked to what extent they define their theoretical orientation as "music as therapy", and to what extent they define it as "music in therapy" on 1 (not at all) to 6 (extremely so) scales ${ }^{5}$. That is, participants were not limited to choose one or the other, but rather had the freedom to define any combination of the two. A two-way repeated measures analysis was conducted where theoretical orientation (music as therapy vs. music in therapy) was a within subject factor and seniority (MEMTs vs. LEMTs) was a between subjects factor. As can be seen in Figure 2, overall, MTs defined themselves in terms of "music in therapy" ( $M=4.5, S D=1.2)$ and less as "music as therapy" ( $M$ $=3.8, S D=1.6 ; F(1,104)=12.6, p<0.01)$. This difference, however, was much more pronounced among the MEMTs than among the LEMTs. With MEMTs, the music as therapy approach was significantly lower than the music in therapy approach $(M=$ $3.6, S D=1.5$ vs. $M=4.7, S D=1.08$, respectively, $t(48)=3.82, p<0.001$ ) while with the LEMTs, the approaches were more evenly distributed $(M=3.9, S D=1.6$ vs. $M=4.4, S D=1.28$, respectively, $t(56)=1.28, p>0.05)$. 


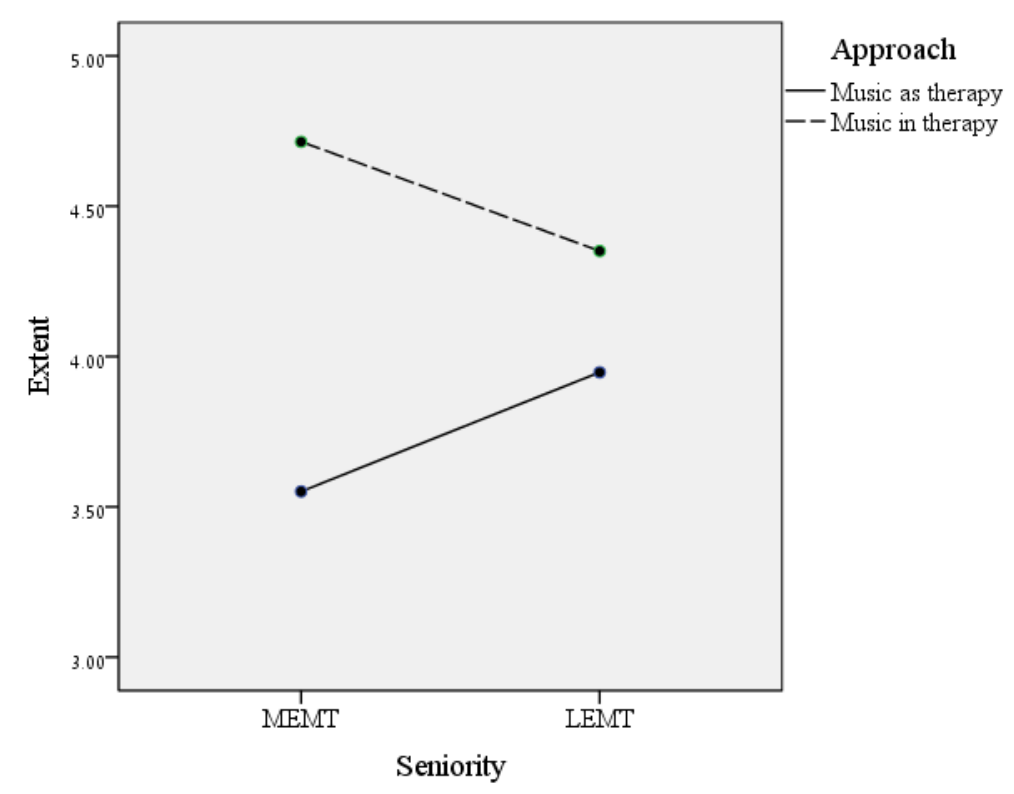

Figure 2

Music therapy approach (music as therapy vs. music in therapy), comparing MEMTs and LEMTs

MTs were asked to refer to the verbal vs. musical orientation of their work, that is, to what extent their work is musically oriented, and to what extent they were verbally oriented. To examine their responses, a repeated measures analysis of variance was conducted with verbal vs. musical orientation in treatment as a within subject factor and with seniority (MEMT vs. LEMT) as a between subject factor. Results (see Figure 3) show that in general, MTs report a more musical $(M=4.6, S D=0.96)$ orientation than a verbal one $(M=3.8, S D=1.21 ; F(1,104)=21.1, p<0.001)$. The difference, however, was much more pronounced for the LEMTs (4.7 musical vs. 3.7 ) than for the MEMTs (4.4 musical vs. 4.0 verbal). That is, less experienced MTs defined their work as more musically oriented and less verbally oriented than the more experienced MTs as is indicated in the significant interaction between the factors $(F(1,104)=4.1, p<$ 0.05).

MTs were asked to indicate what their general theoretical framework was. They could indicate any one of the theoretical frameworks that appear in Table 4 or any combination of the frameworks.

Note. Percentages add up to more than $100 \%$ in each group because participants were free to choose one or more theoretical frameworks.

Overall, MEMTs and LEMTs were quite similar in defining their theoretical framework with humanistic, psychodynamic, and intersubjective frameworks being most frequently mentioned.

\section{Discussion}

The purpose of this study was to examine, as broadly as possible, current Israeli MT practice with reference to MT techniques, client populations, and theoretical orientation. The comparisons we made between experienced and less experienced MTs enabled us to see whether the current situation is static or dynamic and changing, and if so - in what direction. We find such information important because it enables the practice to situate itself in the changing contexts and to respond to different needs. We will discuss each of the main findings in the context of music therapy training in Israel and in comparison to studies conducted in other countries, whenever available. 


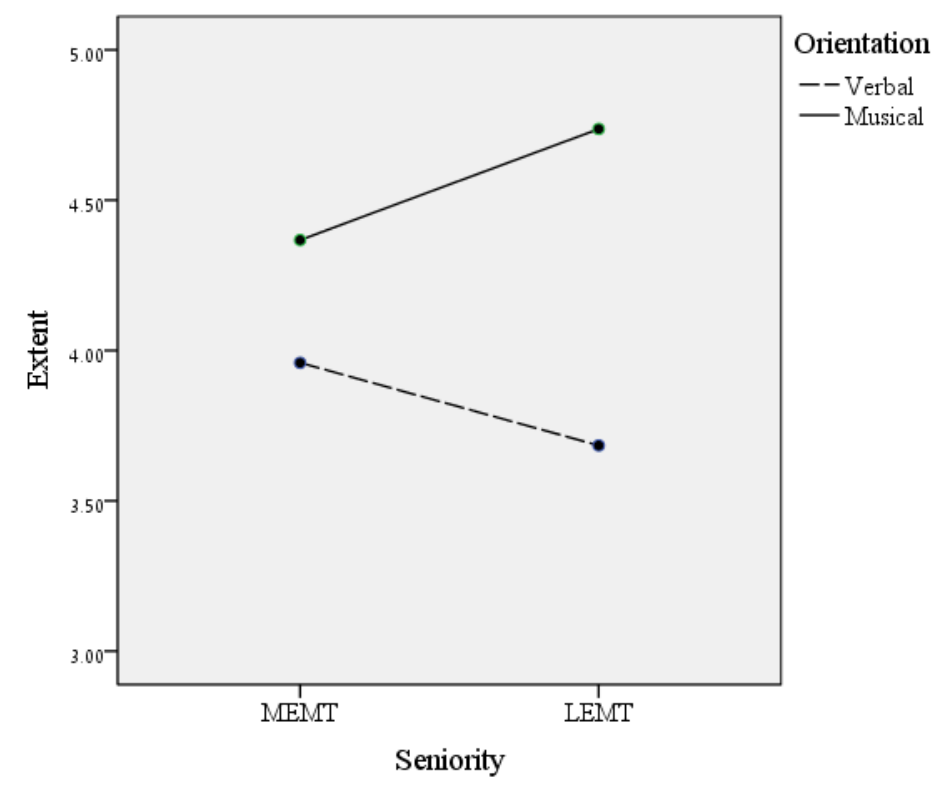

Figure 3

Music therapy orientation (musical vs. verbal), comparing MEMTs and LEMTs

Table 4

Psychological Theoretical Framework of MEMTs and LEMTs (in percentages out of the total number of participants in each group)

\begin{tabular}{|l|l|l|l|l|l|c|}
\hline & \multicolumn{1}{|c|}{ Humanistic } & Psychodynamic & Intersubjective & Developmental & Educational & Cognitive \\
\hline MEMT & 37.5 & 45.8 & 31.3 & 2.1 & 8.3 & 16.7 \\
\hline LEMT & 38.6 & 52.6 & 43.9 & 1.8 & 14.0 & 1.8 \\
\hline
\end{tabular}

\section{Preferred Musical Instruments}

The piano was, by far, the most prevalent instrument among music therapists in this study. Although the guitar was also dominant, especially among the LEMTs, the piano still seems to be the most frequently used musical instrument by MTs in Israel. Other instruments, such as drums and voice, were reported to be used to much lesser extents. Studies conducted in North America have shown a more heterogeneous scene. Goodman (2011), for instance, reported that voice, piano, and guitar are the most common instruments used in music therapy in the United States (and see Cohen, Hadsell \& Williams, 1997 for similar findings). Voyajolu (2009), who surveyed 250 therapists regarding the instruments used most often during music therapy, found that voice (27.6\%) and piano (26.4\%) were the most important instruments while the guitar was ranked lower (7.2\%).

The reason why the piano is so dominant amongst Israeli music therapists could be explained by the focus that it has been given throughout the years (since the early 1980s) in the Israeli music therapy training programs. First of all, according to the entrance requirements stated in guidelines for registering students ${ }^{6}$, most programs required high-level piano skills as an admission criterion, which naturally excluded potential music therapists who had no piano skills but were proficient in other instruments. Secondly, for many years, and in several of the MT programs, improvisation and songwriting courses were encouraged primarily using the piano and only later using other instruments. This might have been the influence of earlier training in the world based on Creative Music Therapy in which the piano was central, although no Creative Music Therapy program exists in Israel. What we see in the programs we head and in other programs is that in the past decade or so, the use of a wider range of instruments 
has been encouraged. Although this piano-oriented trend is passing, as it is in other places in the world (Jenkins, 2013), we suggest that the MEMTs who completed their training more than 8 years ago are still under its influence. This explains why LEMTs were indeed less piano-oriented, more open to other instruments, and more competent with their voices. It seems though, that more should be done to encourage competence with other basic instruments as voice, drums, and guitar, to achieve figures similar to those mentioned in the American surveys. We believe that the more different instruments are included in the music therapists' toolkit, the more inclusive the practice is. It enables candidates with different musical backgrounds to enter the training programs and it eventually enables more potential clients to connect to music and to music-making in the room.

\section{Music Therapy Techniques}

The results showed that Israeli music therapists use a variety of music therapy techniques, the leading ones being instrumental improvisation, work with existing songs, vocal improvisation, and songwriting. This is not a surprise because these techniques are the four most basic "tools" of many music therapists. GIM, in contrast to the others, was rarely used among the respondents in this study. This is probably connected to the fact that no music therapy program in Israel provides GIM training. In this respect it is significant that more than a third of the respondents that expressed a need to develop professionally, mentioned their need for GIM training. If policy makers in Israeli music therapy are to consider this clinical expertise as important for potential music therapy clients, there should be a systematic implementation of GIM training in at least one of the training programs or perhaps as a post-masters diploma or continuing professional development for graduates seeking this path of clinical development. We believe that enabling more paths for music therapists will eventually make music therapy available to more potential clients.

\section{Clinical Populations}

Regarding the clinical populations that were most preferred by the respondents, there was a significant difference between the LEMTs and the MEMTs. While the MEMTs mostly preferred the age group of children and people emotional disabilities as their preferred clientele, the LEMTs were more flexible as to their preferred age groups (toddlers, children, and adolescents) and regarding their preferred clientele groups (emotional disabilities and autism). Respondents, both MEMTs and LEMTs, were less enthusiastic about working with older adults or clientele with intellectual disability, learning disabilities, mental disabilities, physical disabilities, or, youth at risk.

Studies have shown that there are several factors influencing which clientele MTs prefer. Blachman (2012), who interviewed Israeli MTs, found that the choice of population often serves the music therapists in that it enables them to express elements of their personality and that the encounter with the chosen population facilitates coping with personal issues which, in turn, contributes to their growth. Based on a survey in the US, Marrison (in Blachman, 2012), found that the therapist's choice of population stems from the feeling of hope and success and what drives them is the challenge and interest and not necessarily the remuneration. Other studies (Pervin, 1968; Stewart, 2000) found that the work environment (e.g., good communication with colleagues) is a key factor in choosing one clientele or another. It is also important to mention "reality constraints" that have an effect on MTs choice of population. In Israel, for instance, the ministry of education is much more advanced and supportive of music therapists compared to the ministry of health, and therefore, offers more jobs and better conditions. This definitely has an effect on MTs' choices.

It is unclear which of these factors influence MEMTs to prefer a specific and narrow clientele, or what affects LEMTs to have broader preferences. Has something in the perspective of music therapists changed so that they feel it is possible to work in a wider variety of working environments? Or has something changed in the field so that 
new client possibilities such as kindergartens and high-schools opened their gates to MTs? The answers to these questions are still unclear and further research is required to understand the inter-relationships between the field, the MTs, and how the MTs perceive the field in regard to their personal and professional developmental aspirations.

One of our main concerns in this survey is that older adults were not a popular choice among the respondents, despite the growing numbers and needs of potential clients in this age group and the growing developments in the field of gerontology in Israel (Glicksman \& Litwin, 2011). Indeed, research conducted in other countries indicates a similar trend. In Spain there is a growing demand for music therapists in the fields of geriatric music therapy, neurological rehabilitation, psychiatric and medical music therapy (Sabbatella, 2004). In Taiwan, music therapy services for the older adults and individuals dealing with end-of-life issues are increasingly in demand (Lee, 2003). In Norway this field has expanded in recent years (Trondalen, Rolvsjord, \& Stige, 2010). Although more focus is placed on this field in some of the music therapy training programs in Israel (e.g., a course about music and older adults), and in placement in retirement homes, there is definitely a lot more that needs to be done (Dassa, 2012). Other professions such as social work, nursing, and medicine, which have already made such changes, can provide valuable ideas and insight. Gorelik, DamronRodriguez, Funderburk, and Solomon (2000) and Robert and Mosher-Ashley (2000), for instance, found that previous acquaintance with older adults promotes motivation to work with this population and that positive field-experience during training is important and reinforces positive feelings and willingness to work in this field.

\section{Theoretical Orientation}

Measuring the theoretical orientation of MTs is quite difficult and it was therefore approached in several different ways in our survey. One way was to see how music and words were intertwined in music therapy. In general, the respondents of this survey combined music and words, music in therapy, and music as therapy. Interestingly, however, the MEMTs did this in different proportions than the LEMTs. While the MEMTs combined more evenly the verbal and the musical in their sessions, the LEMTs gave more emphasis to the musical. While the MEMTs gave more weight to music in therapy, the LEMTs gave equal weight to music in therapy and music as therapy. Assuming that music as therapy applies more music making than music in therapy, it seems that the younger generation of music therapists is drifting towards making more music in sessions and talking about it to a lesser extent. On the other hand, it could be that the more experience MTs feel more accomplished using both words and music while the less experienced MTs did not gain enough experience using words in therapy. Yet other possibilities to understand the difference between MEMTs and LEMTs is that MEMTs are less comfortable using music or that different client groups require different emphases altogether. Further research might show which of these possibilities is more probable.

A second way to evaluate theoretical orientation is to ask what framework MTs rely on in their work. Here we found that Israeli MTs, both more and less experienced ones, rely on psychodynamic, humanistic, and intersubjective approaches and less on educational, developmental, and cognitive approaches. It seems that the respondents in this survey were geared to psychotherapeutic work, despite the fact that most of the music therapists in the country work with children in schools. It could be argued that developmental, educational, and cognitive approaches would be more suitable for them. This incongruence between what MTs bring to work (i.e., music psychotherapy - perhaps because this is what they were trained to do) and what they ought to be doing (music therapy in educational settings) was brought up in two separate masters theses that examined music therapy in education (Neuman, 2010) and in special education (Amitay, 2011) settings. These two studies found that there is not sufficient preparation of MTs to work within educational environments and that this results in severe communication problems with the educational system. Another possibility is that 
many music therapists in these places are provided with the supervision of psychotherapists, not music therapists, thus not attending the uniqueness of the music therapy setting. Here, too, the conclusions bounce back to the policy makers in the field of music therapy training as to what the emphases should be in the training program and whether these are biased towards one type of music therapy (i.e., psychotherapeutic) at the expense of another (i.e., educational). This point was brought up in both Amitay's (2011) and Neuman's (2010) studies.

It is interesting to contrast the orientation of MTs in Israel to clinical orientations reported in other countries. Undoubtedly, the theoretical orientation of MTs stems from the framework of the training programs and contexts in which practitioners work in that country. It is expected, therefore, that in Denmark where the Aalborg University program is dominant, MTs will abide to the tradition and the concepts of humanism as well as psychodynamic ideas of this school (Bonde, 2007). In Spain we might expect a variety of theoretical orientations reflecting the variety of music therapy training courses in the country. Sabbatella (2004) referred to this and mentioned that in Spain, many music therapy courses are taught by foreign professors who bring different approaches. The theoretical orientation of some music therapy programs is eclectic while others are based on the principles of Benenzon's music therapy that is influential in this country. In Japan, to give one last example, the orientation is said to be either "clinical" or "bio-musical", as a reflection of the two music therapy associations that exist in the country. Okazaki-Sakaue (2003) claimed that the members of the former tend to use psychotherapeutic and humanistic approaches in practice, while the latter focus more on the medical/biological and behavioral aspects and that very few clinicians focus on psychodynamic or music-centered approaches since there is no established training in the country in this field. Apparently, a nation-wide survey such as the one conducted in the present study, could enable more accurate information regarding the approaches adopted by MT in each of these countries.

\section{Summary}

Summing up the findings of this survey makes it possible to obtain a broad picture of the music therapy profession in Israel. This picture can be a helpful tool for music therapy policy makers in deciding how to further develop this field; what are the field's strengths and weaknesses; what should be preserved and maintained and what should be developed and promoted. The main practical points for training programs we came up with in this study are: (1) Enable/encourage instruments other than the piano and the guitar. This is especially important considering Israel's multicultural nature, implying the importance of encouraging the promotion of non-Western MTs and instruments; (2) connected to the first point, embrace a more specific, well-educated, clientappropriate theoretical approach rather than focus on one direction all-encompassing framework, in order to expose the students to a variety of approaches. Especially see how the approaches taught in the programs serve future MTs in the educational field; expose students to new developments in the field of music therapy, such as community music therapy and neurological music therapy; and create opportunities for post graduate studies to learn models such as GIM; (3) Promote opportunities to work with less popular populations such as older adults and clients with physical disabilities. Exposure should begin in the training programs. Although students in the Israeli training programs are typically exposed to a variety of clinical populations (e.g., autistic spectrum disorders, learning disabilities, physical disabilities, mental disabilities, youth at risk) and work in varied places (e.g., parent-child centers, hospitals, rehabilitation centers, psychiatric hospitals, schools, special education schools) there is still a need to identify those populations and locations that are not receiving proper attention.

Despite the fact that this study is a local one, seemingly applicable to Israel only, we believe that it has global implications. Policy makers in different countries can see how the music therapy situation in one country reflects on their own situation. Policy makers can also induce what points in the present survey apply to their country and 
therefore, call for similar actions as recommended here, and what points are different and thus call for a separate survey. One point, however, should stand out in any case: the mere act of surveying music therapists and trying to sketch a picture of our profession is invaluable. We, therefore, highly recommend that researchers in other countries perform similar surveys. A loftier idea, perhaps one that should come after several countries have published their "local" findings, would be to conduct an international survey, in which as many countries as possible are represented, and comparisons and categorizations are made ${ }^{7}$. The varied contexts and needs represented by different countries may lead towards alternative foci or music therapy surveys. An international survey, on the other hand, will offer a broader, overall picture of the practice of music therapy across the globe. Such research will surely enable a great understanding of and therefore development of our profession, at large.

\section{Notes}

1. Replaced by Dr. Dikla Kerem in 2015

2. Recently replaced by Dr. Ayelet Dassa

3. Note that participants were not asked what population they actually worked with because this would result in answers affected by various constraints such as funding, legislation, etc. The present question, therefore, points at the MTs would wish to work with if they had the choice.

4. Note that not all of the 700 MTs that graduated in Israel actually work as MTs and that not all of them are affiliated to an organization or a training program. Therefore, it was not possible to access all 700 Israeli MTs.

5. In 'music as therapy' music is served as the primary stimulus medium and emphasis is given to the client-therapist relationship through music whereas 'music in therapy' put the music as adjacent and not necessarily the primary modality (Bruscia, 1987).

6. Where these could not be found, we manually went through acceptance regulations that were published annually and / or made contact with former heads of music therapy programs and asked them.

7. The World Federation of Music Therapy (WFMT) has conducted such a survey but it has not yet been published.

\section{References}

Amitay, Y. (2011). Attitudes of teachers and paraprofessionals in special education schools towards music therapy. Unpublished thesis, Bar-Ilan University. [In Hebrew].

Blachman, Y. L. (2012). The narrative of choosing a population to work with. In D. Amir \& C. Elefant (Eds.), Listen to my voice: New research studies in music therapy (pp. 257-283). Kiryat Bialik: Ach Publishers.

Bonde, L. O. (2007). Music therapy in Denmark. Voices Resources, Retrieved from, http://www.voices.no/community/?q= monthdenmark january2007.

Bruscia, K. E. (1987). Improvisational models of music therapy. Springfield, IL: Charles C. Thomas.

Clark, M. E., \& Kranz, P. (1996). Attitudes and experiences of new music therapy students. Journal of Music Therapy, 33, 124-146, https://doi.org/10.1093/jmt/33.2.124.

Cohen, N. S., Hadsell, N. A., \& Williams, S. L. (1997). The perceived applicability of applied music requirements in the vocational practices of professional music therapists. Music Therapy Perspectives, 15, 67-72, https://doi.org/10.1093/mtp/15.2.67.

Curtis, S. L. (2013). Women's issues and music therapists: A look forward. The Arts in Psychotherapy, 40(4), 386-393, https://doi.org/10.1016/j.aip.2013.05.016.

Dassa, A. (2012). The narrative of female music therapists regarding their choice to work with Alzheimer's patients. In D. Amir \& C. Elefant (Eds.), Listen to my voice: New research studies in music therapy (pp. 230-256). Kiryat Bialik: Ach Publishers. 
Glicksman, A., \& Litwin, H. (2011). International spotlight: Israel. The Gerontologist, 51(6), https://dx.doi.org/10.1093/geront/gnr104.

Goodman, K. D. (2011). Music therapy education and training: From theory to practice. Springfield, Illinois: Charles C. Thomas Publication.

Gorelik, Y., Damron-Rodriguez, J., Funderburk, B., \& Solomon, D. H. (2000). Undergraduate interest in aging: Is it affected by contact with older adults? Educational Gerontology, 26, 623-638, https://doi.org/10.1080/03601270050200626.

Gottfried, T. (2015). Israel - Country report on professional recognition of music therapy. Approaches, 7(1), 159-160.

Jackson, N. A. (2003). A survey of music therapy methods and their role in the treatment of early elementary school children with ADHD. Journal of Music Therapy, 40, 302-323.

Jenkins, C. (2013). Functional musicianship of music therapy students: Entering internships as perceived by internship directors. Music Therapy Perspectives, 31, 175-180.

Kern, P., Rivera, N. R., Chandler, A., \& Humpal, M. (2013). Music therapy services for individuals with Autism Spectrum Disorder: A survey of clinical practices and training needs. Journal of Music Therapy, 50, 274-303, https://doi.org/10.1093/jmt/50.4.274.

Lee, C. S. (2003). Music therapy in Taiwan. Voices Resources, Retrieved from, http://www.voices.no/community/?q= country/monthtaiwan_november2006.

Neuman, E. (2010). Perceptions and attitudes of teachers and music therapists towards music therapy as a profession in mainstream education schools. Unpublished thesis, Bar-Ilan University. [In Hebrew].

Okazaki-Sakaue, K. (2003). Music therapy in Japan. Voices Resources, Retrieved from, http://www.voices.no/community/?q= country/monthjapan_may2003.

Pervin, L. (1968). Performance and satisfaction as a function of the individual-environment fit. Psychological Bulletin, 69, 56-68, https://doi.org/10.1037/h0025271.

Robert, R., \& Mosher-Ashley, P. M. (2000). Factors influencing college students to choose careers working with elderly persons. Educational Gerontology, 26, 725-736, https://doi.org/10.1080/036012700300001386.

Sabbatella, P. L. (2004). Music therapy in Spain. Voices Resources, Retrieved from, http://www.voices.no/community/?q= country/monthspain_march2004.

Sheehan, K. B. (2001). , E-mail survey response rates: A review. Journal of Computer-Mediated Communication, 6(2), https://doi.org/10.1111/j.1083-6101.2001.tb00117.x.

Silverman, M. J. (2007). Evaluating current trends in psychiatric music therapy: A descriptive analysis. Journal of Music Therapy, 44, 388-414, https://doi.org/10.1093/jmt/44.4.388.

Stewart, D. (2000). The state of the UK music therapy profession- personal qualities, working models, support networks and job satisfaction. British Journal of Music Therapy, 14(1), 13-27.

Trondalen, G., Rolvsjord, R., \& Stige, B. (2010). Music therapy in Norway - Approaching a new decade. Voices Resources, Retrieved from, http://www.voices.no/ community/?q= country-of-the-month/2010-music-therapy-norway-approaching-newdecade.

Voyajolu, A. (2009). The use of the music therapist's principal instrument in clinical practice. New Jersey: Montclair State University. Unpublished masters thesis. 